\title{
Study of a dielectric barrier discharge burner for plasma assisted combustion
}

\author{
Alena Sludnova ${ }^{1,2}$, Nikolay Mironov ${ }^{1}$, and Paul Mikheyev ${ }^{1,2^{*}}$ \\ ${ }^{1}$ Samara National Research University, 443086, Samara, Russia \\ ${ }^{2}$ P N Lebedev Physical Institute, 443011, Samara, Russia
}

\begin{abstract}
In this short communication we report the results of measurements of the number densities of $\mathrm{O}_{3}, \mathrm{NO}$ and $\mathrm{NO}_{2}$ in the afterglow of a dielectric barrier discharge. Detailed modelling of plasma processes in a DBD is a challenging task and this data is necessary for verification of numerical model. The DBD in air produced only $\left[\mathrm{O}_{3}\right]$ up to $\sim 10^{16} \mathrm{~cm}^{-3}$ and [NO] up to $\sim 5 \times 10^{14} \mathrm{~cm}^{-3}$ that increased with discharge power linearly. In air fuel mixtures $\left[\mathrm{O}_{3}\right]$ was an order of magnitude smaller, it decreased with $\left[\mathrm{CH}_{4}\right]$. In methane-air mixture $\mathrm{NO}$ was not detected, but $\left[\mathrm{NO}_{2}\right]$ up to $\sim 10^{15} \mathrm{~cm}^{-3}$ appeared instead.
\end{abstract}

\section{Introduction}

Low temperature nonequilibrium plasma is an efficient tool for speeding up chemical processes relative to combustion, and extensive studies of plasma ignition and plasmaassisted combustion are under way at present [1,2]. For example, a repetitively pulsed nanosecond discharge with a low duty cycle [3] in an air-fuel flow permitted to achieve ignition, flame holding and steady combustion downstream of the discharge at low pressure of 60 Torr. The reduced electric field $E / N$ in this type of discharge is on the order of hundreds of $\mathrm{Td}$ and large numbers of energetic electrons efficiently dissociate, ionize and excite gas molecules. However, with pressure one needs to increase a discharge current substantially to fill the discharge gap with plasma. Therefore, at larger pressures, scaling of this type of discharge does pose technical problems due to large pulsed discharge current.

Dielectric barrier discharge (DBD) is of special interest in this field, because it is able to provide plasma with a large $E / N$, too, even at an atmospheric pressure. It operates in a wide pressure range, quite simple to design, has an ability to be easily integrated in different flow configurations. At an atmospheric pressure, its current density is on the order of $100 \mathrm{~mA} \mathrm{~cm}^{-2}$ and voltage across the electrodes with $1 \mathrm{~mm}$ gap in air-fuel mixture is about $6 \mathrm{kV}$. DBD consists of a large number of streamers of a nanosecond duration with a large $E / N$ in their heads and is able to ionize, dissociate and excite molecules efficiently. Detailed modeling of plasma processes in a DBD that lead to ignition of an air-fuel mixture is a challenging task, but it can be simplified if we try to calibrate the model first, measuring the number density of products that appear in the plasma afterglow before ignition.

\footnotetext{
* Corresponding author: paulmikheyev@,hotmail.com
} 
The aim of this work was to measure $\mathrm{O}_{3}, \mathrm{NO}$ and $\mathrm{NO}_{2}$ number densities in the afterglow of a DBD in an air-methane mixtures with intention to use this data for verification of numerical modeling.

\section{Experiment}

The sketch of the experimental setup is shown in Figure 1. A diffuse DBD was obtained in a coaxial burner. The burner was made out of a quartz tube $16 \mathrm{~mm}$ inner diameter and 1.5 $\mathrm{mm}$ wall thickness. The gap between the inner anodized aluminum electrode and the tube wall was $1 \mathrm{~mm}$. An outer electrode was a fine steel mesh $5 \mathrm{~mm}$ long along the tube wall, providing a homogeneous discharge in air [4] and $\mathrm{CH}_{4}$ :Air mixtures.

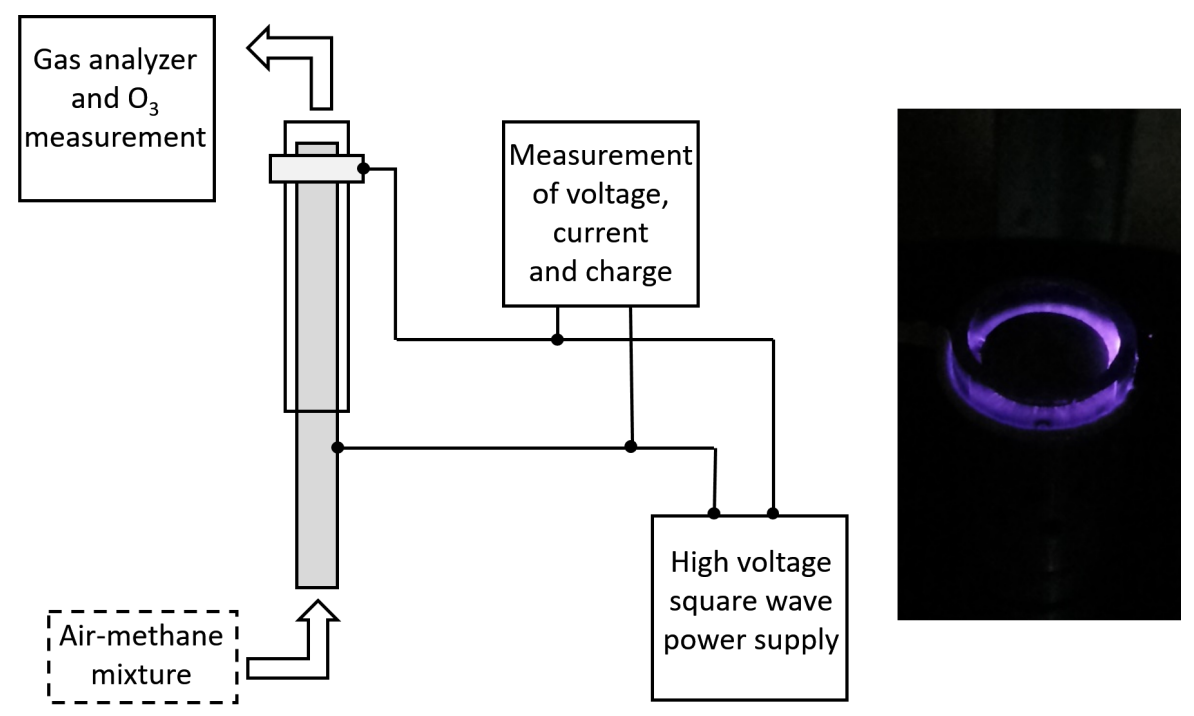

Fig. 1. Experimental setup and a photograph of the DBD from above at an angle.

Voltage, applied to the electrodes, discharge current and transferred charge were measured with the help of a voltage divider, a Rogowski coil and a capacitor in series with the discharge. Discharge power was determined by calculating the area of Lissajous figures in the voltage-charge coordinates, which is a standard technique for a DBD. Discharge started at $\sim 6.5 \mathrm{kV}$. Power load into the discharge was on the order of $10 \mathrm{~W}$. Small discharge gap prevented ignition of $\mathrm{CH}_{4}$ :Air mixtures.

Ozone number density was measured by absorption of $255 \mathrm{~nm}$ radiation from a LED. Commercially available gas analyzer GMS-810 measured the number densities of nitrogen oxides downstream of a cell for $\mathrm{O}_{3}$ measurement.

\section{Results and discussion}

In dry air the ozone number density $\left[\mathrm{O}_{3}\right]$ was on the order of $10^{16} \mathrm{~cm}^{-3}$, as represented in figure 2 , and exhibited a linear dependence on discharge power. 


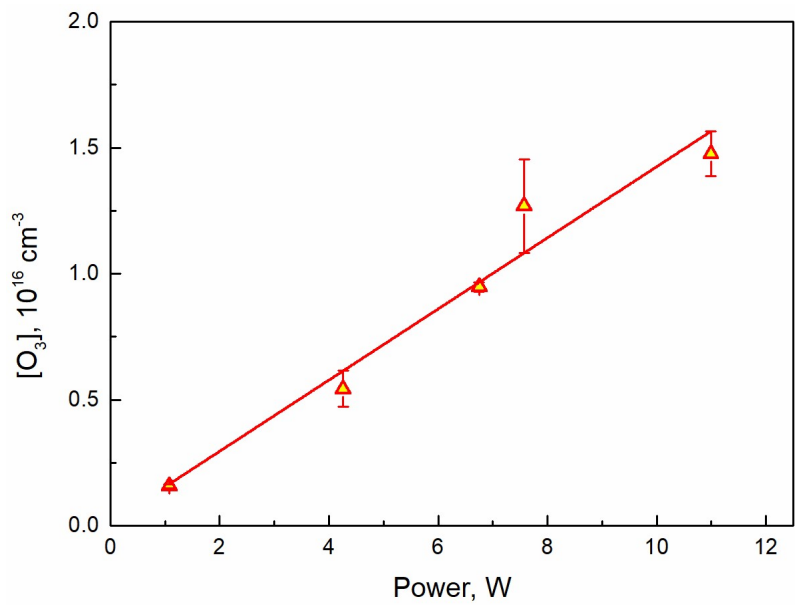

Fig. 2. Ozone number densities in dry air.

In methane-air mixtures $\left[\mathrm{O}_{3}\right]$ was only on the order of $10^{15} \mathrm{~cm}^{-3}$, decreased with methane content and exhibited linear dependence on discharge power, too, as shown in figure 3 .

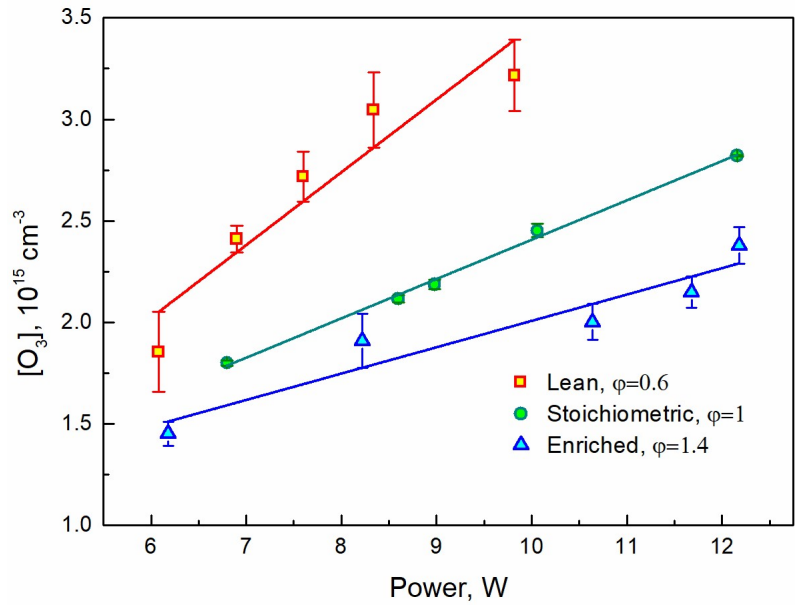

Figure 3. Ozone number densities for different methane-air mixtures.

Measurements of the number densities of nitrogen oxides for air revealed that DBD in air produced only $\mathrm{O}_{3}$ and $\mathrm{NO}$ that increased with discharge power linearly. Apparently, $\mathrm{NO}_{2}$ was beyond the detection limit of the gas analyzer.

In stoichiometric methane-air mixture $\left[\mathrm{O}_{3}\right]$ was an order of magnitude smaller, NO was not detected, but $\mathrm{NO}_{2}$ appeared instead. The results of $\mathrm{NOx}$ measurements are in figure 4. 


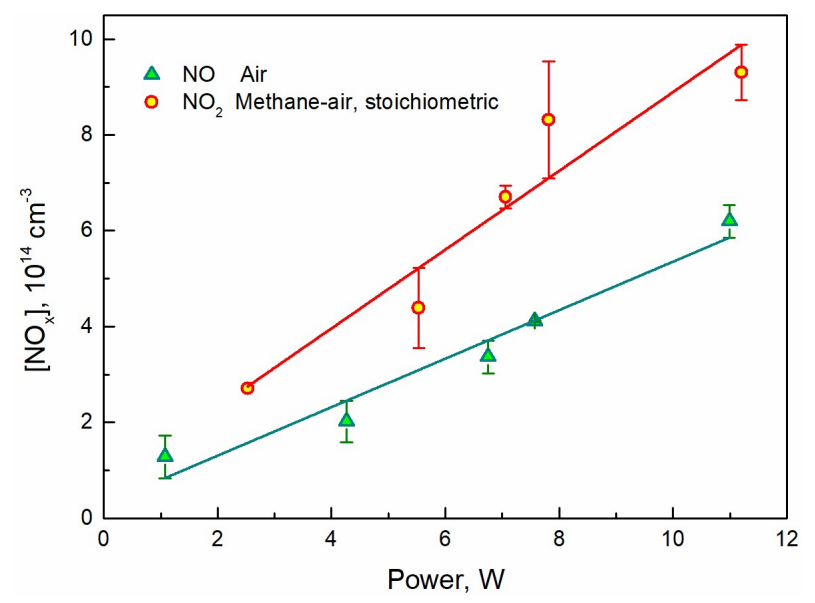

Figure 4. Results of NOx measurements in air an in stoichiometric methane-air mixture.

Qualitatively, our NOx measurements agree with the results reported in $[5,6]$.

This work was supported by the Ministry of Education and Science of the Russian Federation under the Grant No. 14.Y26.31.0020 to Samara University.

\section{References}

1. A. Starikovskiy, N. Aleksandrov, Progress in Energy and Comb. Sci. 39, 61 (2013)

2. S. M. Starikovskaia, J. Phys. D: Appl. Phys. 47, 353001 (2014)

3. A. Bao, Y. G. Utkin, S. Keshav, G. Lou, I. V. Adamovich, IEEE Trans. on Plasma Sci. 35, 1628 (2007)

4. S. Okazaki, M. Kogoma, M. Uehara and Y. Kimura, J. Phys. D: Appl. Phys. 26, 889 (1993)

5. T. Namihira, S. Tsukamoto, D. Wang, S. Katsuki, H. Akiyama, R. Hackam and K. Okamoto, "Pulsed Power Conference, 1999. Digest of Technical Papers. 12th IEEE International," in Production of nitric monoxide in dry air using pulsed discharge, Monterey, (1999)

6. N. Rehbein and V. Cooray, Journal of Electrostatics 51 333, (2001) 